\title{
Evaluation of flood risks using flood frequency models: a case study of Luvuvhu River Catchment in Limpopo Province, South Africa
}

\author{
L. R. Singo ${ }^{1,2}$, P. M. Kundu ${ }^{2}$, F. I. Mathivha ${ }^{2} \&$ J. O. Odiyo ${ }^{2}$ \\ ${ }^{1}$ Process Technology Department, Rand Water, South Africa \\ ${ }^{2}$ Department of Hydrology and Water Resources, \\ University of Venda, South Africa
}

\begin{abstract}
The Luvuvhu River Catchment has experienced floods of varying magnitudes resulting from heavy rainfall associated with the Intertropical Convergence Zone and cyclones. Human activities in the catchment have aggravated risks of flooding. Risks of flooding have been experienced in the past, with the major ones occurring during sporadic rainfall events. This study aims to evaluate flood risks through rainfall distribution characteristics in the catchment using flood frequency models. Statistical analyses that include Gumbel and LogPearson Type III distributions were selected to perform flood frequency analysis. Peak flood magnitudes for the 2, 5, 10, 25, 50, 100 and 200-year recurrence intervals were estimated using the two distributions. In peri-urban areas such as the Luvuvhu River Catchment, design life of structures for low risks (10-year return periods) and medium risks (50-year return periods) catchments are important to manage risks. The results showed a general increase in the frequency of extreme events, accompanied by floods of higher magnitude. Design life of structures for low risks and medium risks catchments showed magnitudes in the range of $453.03 \mathrm{~mm}$ to $1495.48 \mathrm{~mm}$ for Log-Pearson Type III and $454.39 \mathrm{~mm}$ to $1370.16 \mathrm{~mm}$ for Gumbel's. The detected amounts could be taken as the estimated limiting values for flood design purposes in the catchment. Keywords: catchment, design life, flood frequency models, flood magnitudes, flood risk, Intertropical Convergence Zone.
\end{abstract}




\section{Introduction}

The Luvuvhu River Catchment is a predominantly semi-arid region where precipitation is the limiting factor. In this region, rainfall exhibits distinct seasonality within each year with a large quantity of rainfall received between October and March. Risks of flooding have been experienced in the past, with the major ones occurring during sporadic rainfall events. Over the years, the catchment has experienced floods resulting from heavy rainfall associated with the Intertropical Convergence Zone (ITCZ). The ITCZ follows distinct seasonal meridional propagation across the region, and is often associated with rainfall because of extensive convection and cloud development that occur at the location of the ITCZ (Dyson and van Heerden [1]). As a result, tropical cyclones and wave depressions with distinctive fronts, which are associated with the ITCZ, are generally more effective in flooding the catchment.

A number of human induced factors such as deforestation of catchment areas and increased population density along river banks also contribute to floods in the catchment (Duaibe [2]). An increase in population have led to clearing of forests to make way for new activities in the area, such as agricultural fields and human settlements, leaving the area bare and susceptible to flooding.

The present study attempts to evaluate the flood risks through rainfall distribution characteristics in the catchment using flood frequency models. These models can be used to provide information on the probability of flood events so that infrastructures are built accordingly, and human lives are protected (Pegram and Parak [3]). Accurate estimation of flood magnitudes increases safety of the structures and minimize risks. As the catchment is ill-prepared for the heavy summer rains that cause flooding, flood frequency modelling will provide early warnings when heavy rains are anticipated to occur to avert infrastructure damage and loss of life. Figure 1 shows flood waters at Pafuri gate after the Luvuvhu River overflowed following heavy rains while Figure 2 shows a road swept away by strong flood waters along Pafuri villages in the Kruger National Park. All these events led to hardships among the poor, and loss of life.

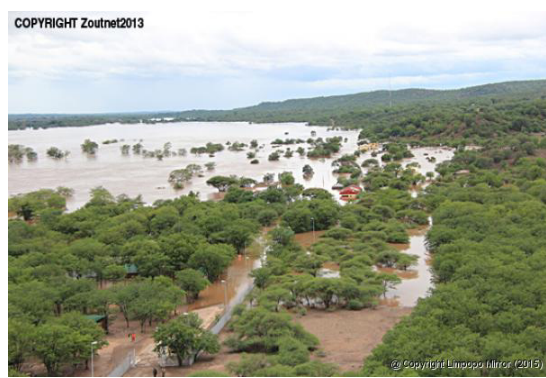

Figure 1: Floods at Pafuri gate after Luvuvhu River overflowed.

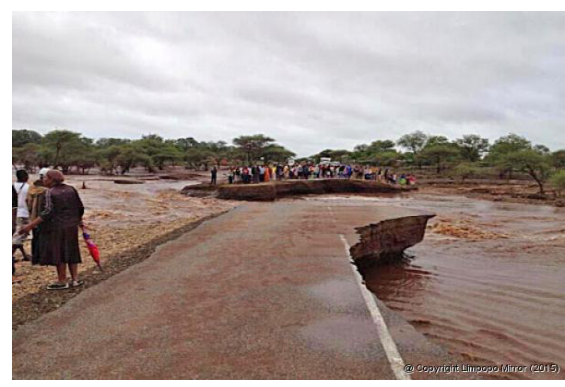

Figure 2: Road swept away by flood waters along Pafuri. 


\section{The study area}

The Luvuvhu River Catchment (shown in Figure 3) is located in Vhembe District in Limpopo Province of South Africa, between latitudes $22^{\circ} 17^{\prime} 57^{\prime \prime S}$ and $23^{\circ} 17^{\prime} 31^{\prime \prime S}$ and longitudes $29^{\circ} 49^{\prime} 16^{\prime \prime} \mathrm{E}$ and $31^{\circ} 23^{\prime} 02^{\prime \prime} \mathrm{E}$. The catchment lies at the periphery of the southernmost position of the ITCZ during the southern summer with average January position at about $15^{\circ} \mathrm{S}$. Rainfall in the region is characterized by large intraseasonal, intra-annual and longer-scale variability and is associated with the ITCZ with its position being determined by the sun [4].

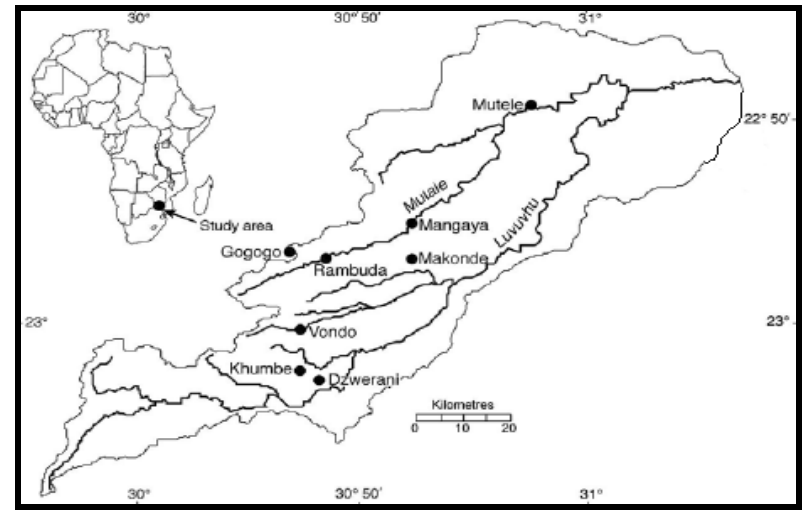

Figure 3: The study area.

\section{Materials and methods}

\subsection{Data}

The study used a 54-year record (1960-2014) of annual maximum rainfall and streamflow series to evaluate the risks of flood in the catchment. The South African Weather Services (SAWS) provided monthly rainfall data while the South African Department of Water and Sanitation (DWS) provided streamflow data. In each given year, the highest event was selected as the maximum value of that year, thereby producing annual maximum series data. The SAWS and DWS have numerous gauges in the catchment which are used to record the rainfall and streamflow on daily basis. Some of the stations missed some data and these were then filled using the interpolation from data of the nearest neighbouring stations. Rainfall was measured in millimetres $(\mathrm{mm})$; such that 1 millimetre of rainfall is rainfall equivalent to 1 litre of water in a 1 square meter box with no runoff, infiltration, or evaporation. Streamflow were measured in cubic metre per second $\left(\mathrm{m}^{3} / \mathrm{s}\right)$.

Eight rainfall stations with long records of data were used in this study. Due to the inadequacy of interpolation and regression techniques when the spatial distribution of stations is skewed, a "driver" station approach was selected for 
use, where Nooitgedacht $\left(-23^{\circ} 07^{\prime} \mathrm{S} ; 30^{\circ} 20^{\prime} \mathrm{E}\right)$ and Palmaryville $\left(-22^{\circ} 98^{\prime} \mathrm{S}\right.$; $\left.30^{\circ} 43^{\prime} \mathrm{E}\right)$ rainfall stations were selected to represent the upstream and downstream catchments, respectively. Annual maximum streamflow series for Luvuvhu River along Nooitgedatcht and Palmaryville, which comprised of gauging weirs $\mathrm{A} 9 \mathrm{H} 023\left(-23^{\circ} 08^{\prime} \mathrm{S} ; 30^{\circ} 17^{\prime} \mathrm{E}\right)$ and $\mathrm{A} 9 \mathrm{H} 003\left(-22^{\circ} 89^{\prime} \mathrm{S} ; 30^{\circ} 52^{\prime} \mathrm{E}\right)$ was used to describe the variability of flood flow in the catchment, in contrast to annual maximum rainfall series. Figure 4 shows the spatial distribution of the selected stations in the catchment.

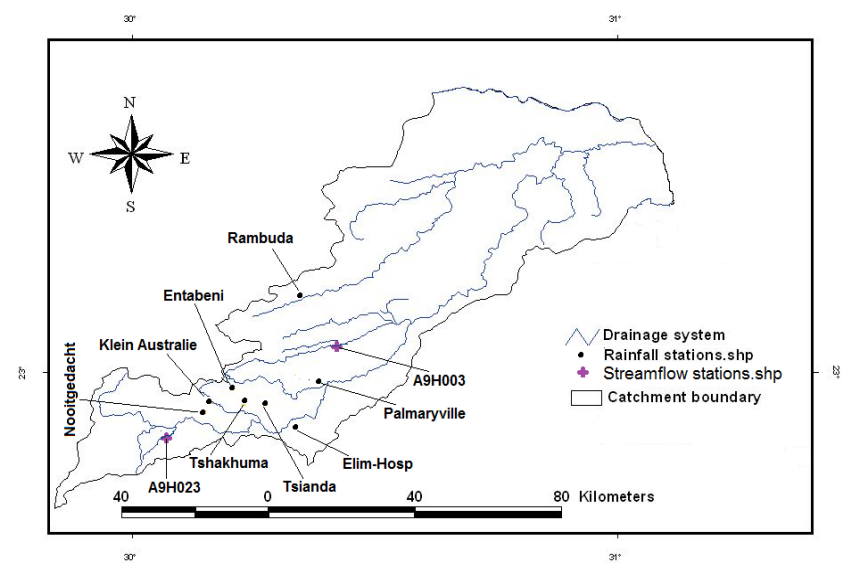

Figure 4: Spatial distribution of selected stations in the catchment.

\subsection{Flood frequency analysis}

To mitigate the risks associated with flood, measurements and analysis for extreme annual rainfall events were estimated using flood frequency models. A comparison of different flood frequency models was made using EasyFit software version 5.5 from MathWave Technologies (Drokin [5]) in order to select the distribution(s) that could be used to model design floods in the study area. The data was ranked according to Weilbull's plotting position and the corresponding return period was estimated.

Based on the probability plots, the distribution with the highest frequency was selected to ensure that designs should be chosen based on the best model testing and validation. Four frequency distributions including the Generalized Extreme Value, the Gumbel's, the Log-normal and the Log-Pearson type III distributions were compared for flood estimation. Gumbel [6] and Log-Pearson Type III distributions (Pearson [7]) models provided the best fit and were selected to perform flood frequency analysis. Peak flood magnitudes for seven different flood levels, 2, 5, 10, 25, 50, 100 and 200-year recurrence intervals, were estimated for flood prevention and protection in the catchment. Each computed flood magnitude was determined at 95-percent confidence interval which contained the true flood magnitude for a particular exceedance probability. 
Gumbel's distribution is based upon the assumption that the cumulative frequency distribution of the largest values of samples drawn from a large population can be described by eqn (1):

$$
P\left(X \geq X_{0}\right)=1-e^{-e^{-y}}
$$

where $P=$ the probability of occurrence, $X=$ the event of the hydrologic series, $X_{0}=$ the desired value of the event and $y=$ is a dimensionless variate given as:

$$
y=\alpha(X-\beta)
$$

where $y=$ the variate value, $\beta=x-0.45005 \sigma_{x}$ and $\alpha=1.2825 / \sigma_{x}$.

$\sigma_{x}=$ standard deviation of variate $X$ and $x=$ mean of the variate $X$. The variate can thus be calculated as:

$$
y=\frac{1.2825(x-\bar{x})}{\sigma_{x}}+0.577
$$

where values 1.2825 and 0.577 are the constants for the reduced mean and reduced variate, respectively.

The Log-Pearson Type III distribution uses log transformation of the data as a base method for flood flow frequency studies as:

$$
X_{T}=\log Q_{T}=X_{a v}+K \sigma_{x}
$$

where: $X_{T}=$ estimated flood values, $Q_{T}=$ the flood for the estimated T-year return period, $K=$ the probability factor based on n-years recurrence interval, $X_{a v}=$ the mean of the logarithms of annual maximum series at the gauging station, and $\sigma_{x}=$ the standard deviation about the mean of the logarithms of annual maximum series.

\subsection{Recent flood risks in Luvuvhu River Catchment}

In recent years, the Luvuvhu River Catchment has experienced severe floods of different magnitudes due to high rainfall events. Lives have been lost due to structural failure of bridges, houses and roads. In the year 2000, 23 people in Thohoyandou, Giyani, Messina and Makhado towns lost their lives through floods while thousands were left homeless. In the 2013 floods, transportation was affected and several leaners lost their lives while attempting to cross flooded streams and bridges as documented by Sowetan [8] and Mail \& Guardian [9] newspapers. During this time, Luvuvhu River at Nandoni Dam overtopped its banks and flooded the riparian zones causing malaria as well as deaths of fauna and flora. In the early summer of 2015, learners missed their studies as most of the roads were under water and destroyed by floods South African Broadcasting Corporation (SABC) [10]. Also, schools and houses were destroyed as they could not withstand the heavy rains.

In all these disasters, the communities were ill prepared for the heavy summer rains that have caused flooding in the catchment. However, much of the damage 
and loss of life could have been avoided by better planning and more investment in disaster management strategies [11]. Municipalities in the catchment did not have disaster management plans and lacked the resources or capacity to properly implement them. People were left destitute as an early warning system for the community was not provided. Flood frequency analysis is therefore fundamentally important in the planning, design and operation of hydraulic structures and for the preservation of human life and property. Figures 5 and 6 further show the aftermath of floods in the catchment.

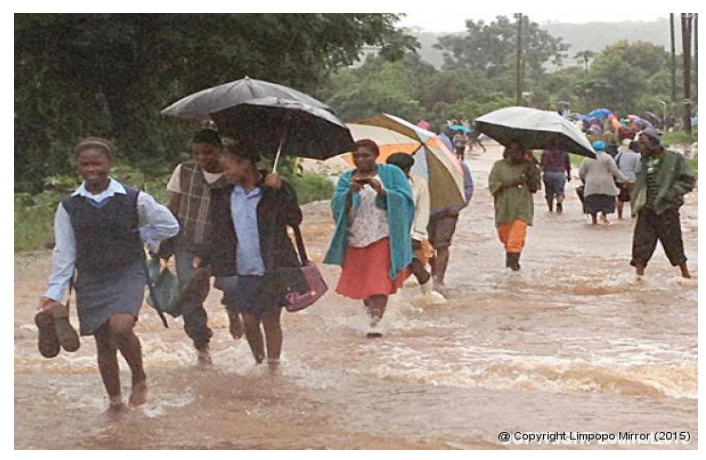

Figure 5: Road under water at Mutale Municipality.

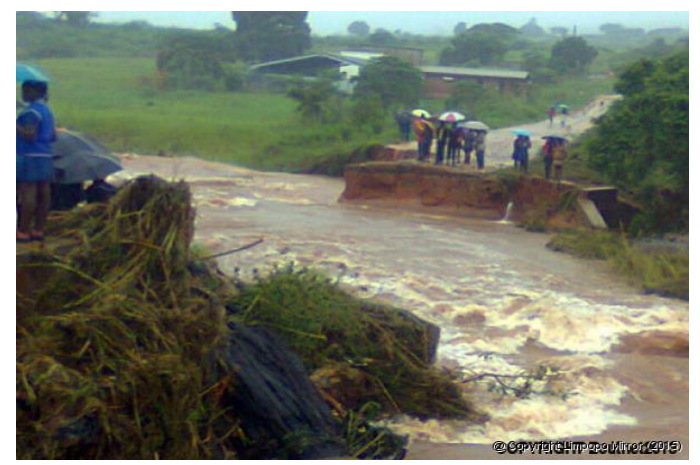

Figure 6: Road washed away during heavy floods at Thulamela Municipality.

\section{Results and discussion}

\subsection{Annual maximum series}

Since rainfall events are highly variable, a 5-year moving average was smoothed in the data to highlight significant changes in the trends. The 5-year moving average curve was found useful in identifying long-term trends in both rainfall and streamflow series. The smoothed trends showed significant hydrological conditions which may suggest that erratic rainfall and catchment characteristics 
such as land use may have caused flood peaks to increase in the area over recent years. The catchment depicted unimodal peaks recorded during the 1999/2000 hydrological year at Nooitgedatcht, Palmaryville, and gauging weir A9H023; except gauging weir A9H003 whose highest measured flow was recorded during the $1976 / 1977$ hydrological year.

The two rainfall stations detected standard variates of $304.4 \mathrm{~mm}$ and $270 \mathrm{~mm}$ and mean coefficient of variability $(C v)$ of 0.64 and 0.52 , respectively. Gauging weirs A9H023 and A9H003 detected standard variates of $1.42 \mathrm{~m}^{3} / \mathrm{s} 22.30 \mathrm{~m}^{3} / \mathrm{s}$ respectively and a mean $C v$ of 0.99 and 0.91 , respectively. The $C v$ values obtained indicated that the distribution of flood flows was highly variable. The variability in flood flow may be attributed to varying hydrological phenomena responsible for generating the flood events in catchment.

Figures 7 and 8 show the distribution of extreme rainfall events upstream and downstream of the catchment. The figures provided valuable insight into the

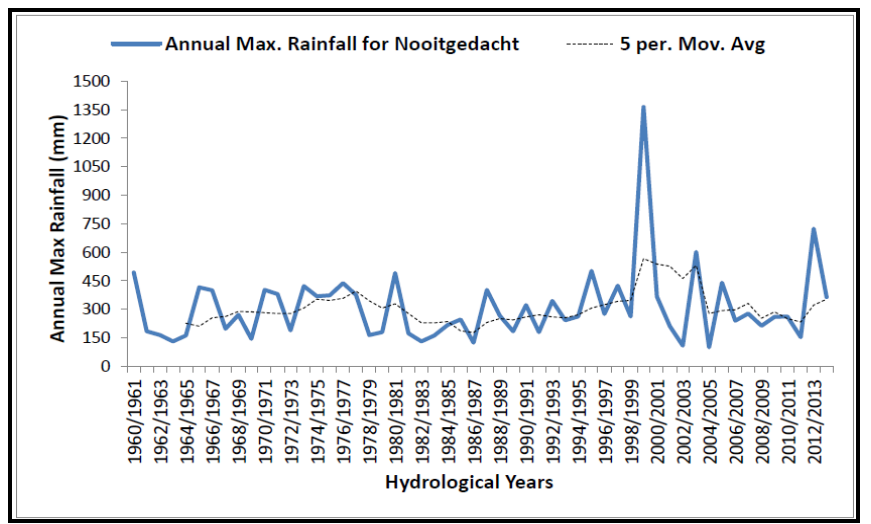

Figure 7: Annual maximum rainfall upstream at Nooitgedacht.

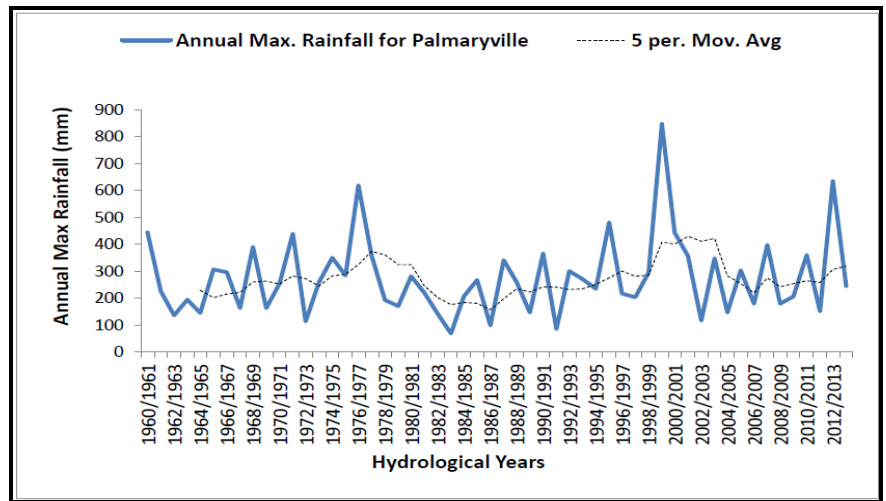

Figure 8: Annual maximum rainfall downstream at Palmaryville. 


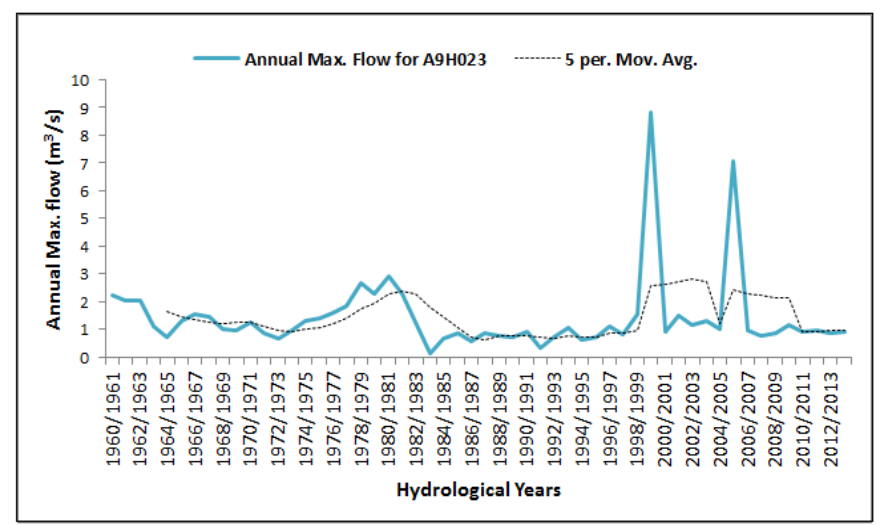

Figure 9: Annual maximum streamflow upstream at A9H023.

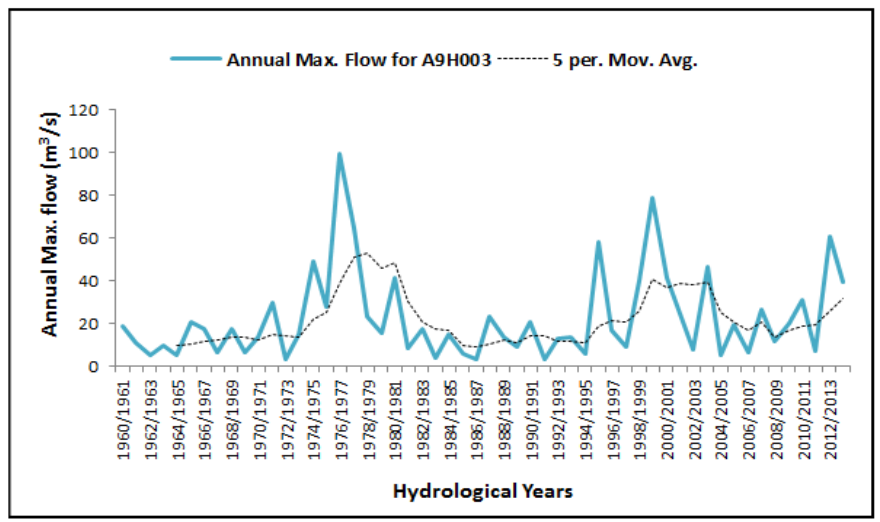

Figure 10: Annual maximum streamflow downstream at A9H003.

trends of the past, and presented a foundation for predicting future trends. The rainfall received at upstream was crucial within the catchment because it affected the amount of water thereof and the flow of the river downstream. Figures 9 and 10 highlighted the annual maximum streamflow trends for stream gauges A9H023 and A9H003 during the same period.

\subsection{Flood frequency and probability of events}

In peri-urban areas such as the Luvuvhu River Catchment, design life of structures for low risks (10-year return periods) and medium risks (50-year return periods) catchments are important to manage risks. Design life of structures for low risks and medium risks catchments at 8 rainfall stations showed magnitudes in the range of $453.03 \mathrm{~mm}$ to $1495.48 \mathrm{~mm}$ for Log-Pearson Type III and $454.39 \mathrm{~mm}$ to $1370.16 \mathrm{~mm}$ for Gumbel's, which could be taken as the rainfall frequency estimation for flood design in the catchment. 
For both upstream and downstream catchments, Figures 11 and 12 were used to present frequency analysis. The figures show that the Gumbel model predicted higher magnitudes than those estimated by the Log-Pearson Type III distribution. Gumbel's 10-year rainfall events estimated peaks of $591.76 \mathrm{~mm}$ and $477.55 \mathrm{~mm}$ upstream and downstream respectively; while the events associated with a recurrence interval of 50 years had flood magnitudes of $870.46 \mathrm{~mm}$ and $678.84 \mathrm{~mm}$. Gumbel's 10-year streamflow events estimated peak flood of $36.99 \mathrm{~m}^{3} / \mathrm{s}$ and $50.77 \mathrm{~m}^{3} / \mathrm{s}$ upstream and downstream respectively; while recurrence interval of 50 years had flow magnitudes of $58.32 \mathrm{~m}^{3} / \mathrm{s}$ and 79.35 $\mathrm{m}^{3} / \mathrm{s}$, respectively.

The Log-Pearson Type III distribution's 10-year flood events predicted peak floods of $517.67 \mathrm{~mm}$ and $453.03 \mathrm{~mm}$ while 50-year events had flood magnitudes of $836.91 \mathrm{~mm}$ and $654.64 \mathrm{~mm}$, respectively. The annual maximum streamflow events showed flood magnitudes of $27.21 \mathrm{~m}^{3} / \mathrm{s}$ and $44.81 \mathrm{~m}^{3} / \mathrm{s}$ of 10 -year flood events upstream and downstream; while the 50-year flood events predicted peak flow magnitudes of $46.88 \mathrm{~m}^{3} / \mathrm{s}$ and $93.07 \mathrm{~m}^{3} / \mathrm{s}$, respectively.

A regression equation was fitted in Figures 11 and 12 to detect a relationship between annual maximum rainfall series and return periods, to test whether such a relationship, either assumed or calculated, was statistically significant. Gumbel analysis detected coefficient of determination $\left(R^{2}\right)$ value of $0.999(100 \%)$ both upstream and downstream of the catchment. Conversely, the Log-Pearson Type III distribution detected $R^{2}$ values of $0.991(99 \%)$ and $0.9998(100 \%)$ for upstream and downstream respectively.

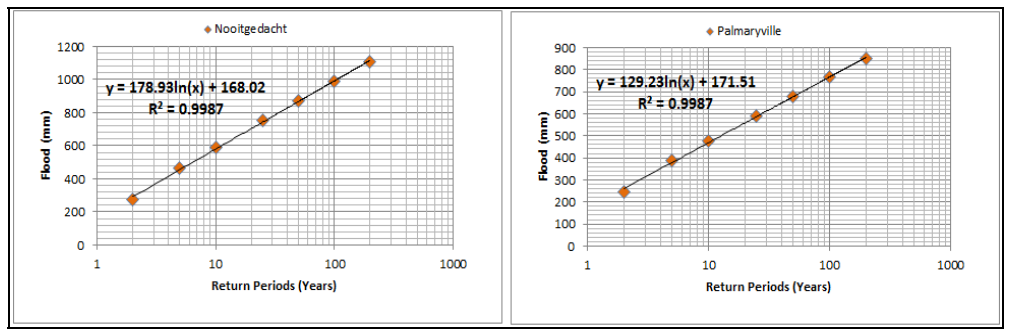

Figure 11: Estimated flood magnitudes for 2, 5, 10, 25, 50, 100 and 200-year return periods using Gumbel's distribution.

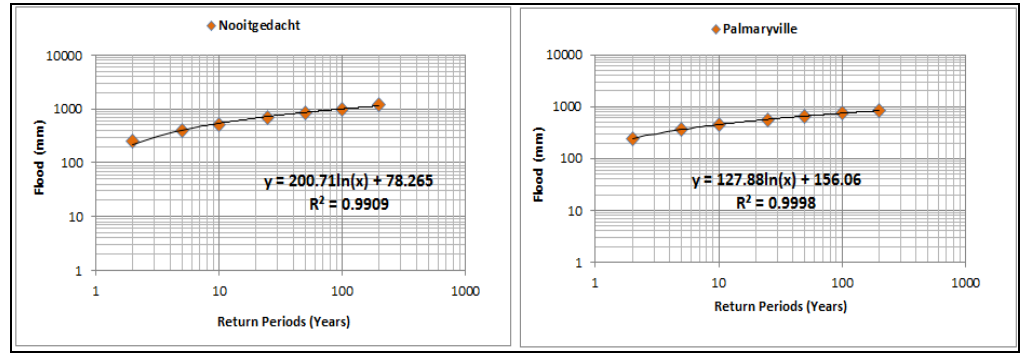

Figure 12: Estimated flood magnitudes for 2, 5, 10, 25, 50, 100 and 200-year return periods using Log-Pearson Type III distribution. 
These predictions can be considered beneficial to the community of Luvuvhu River Catchment and their environment at large as they can save the destructions caused by floods. The two models showed the highest peak events which could be taken as the estimated limiting values for design purposes in the catchment, especially for the 100 and 200-year return periods, which showed very large amounts of over $1000 \mathrm{~mm}$. Given the rapid land use changes in the catchment, a significant rise in river discharges and dam water levels would lead to an increase in potential flood damages, particularly for flood events of lower to medium extremity, reducing flood security for existing protection facilities.

\subsection{Goodness of fit measure}

Streamflow data was used to show the goodness fit of the four tested distributions (Figure 13). The histogram of annual maximum flood data revealed a positive skewed distribution that showed a unimodal distribution which was skewed to the right. Probability density functions (PDF) showed that the Generalized Extreme Value, the Gumbel's, the Log-normal and the Log-Pearson type III distributions were most likely to best fit the data, however, the Log Normal and Log Pearson Type III exhibited similar probability densities which were different from that of the Generalised Extreme Value and Gumbel's distributions. Hence, the Gumbel's and Log Pearson Type III distributions were able to predict floods of higher magnitude events than other distributions. The cumulative distribution function (CDF) showed the non-exceedance probability for a given magnitude. The probability-probability plot showed how well a

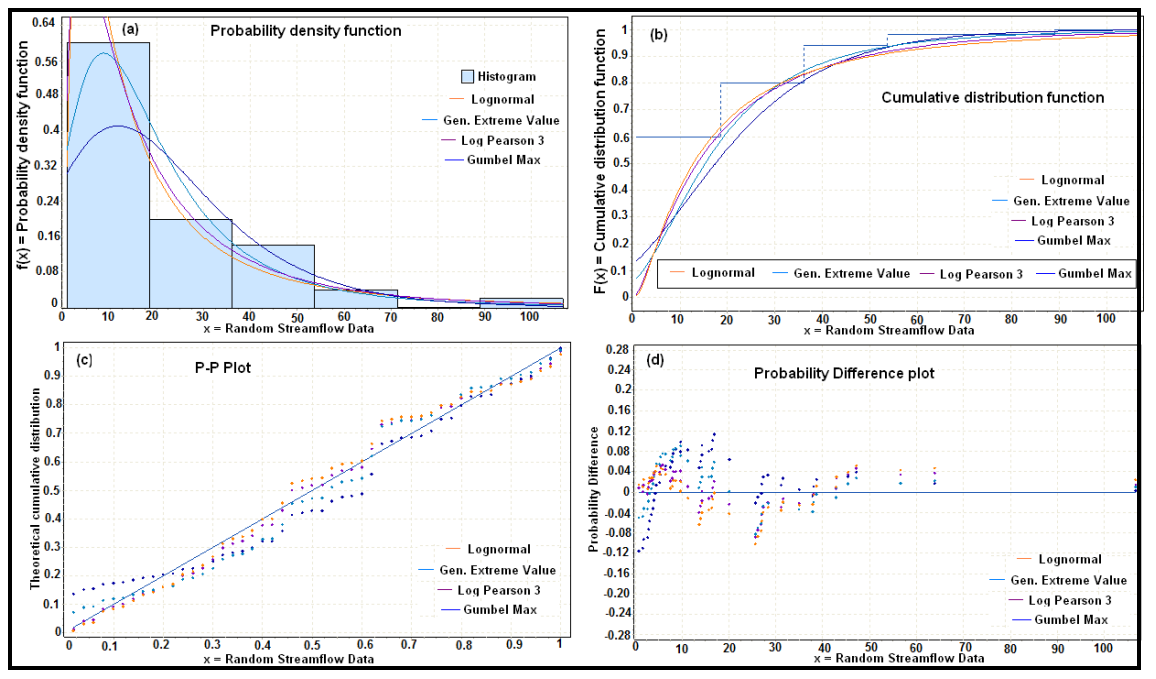

Figure 13: (a) Probability density functions, (b) cumulative distribution functions, (c) probability-probability plots and (d) probability difference for the four compared frequency distributions. 
specific distribution fitted to the observed data. It is recommended that if the maximum absolute difference is less than 0.05 (or 5\%) the fit can then be considered good. For very good fits, this value will be less than $1 \%$.

\section{Conclusion and recommendations}

The analysis of flood frequency showed increasing floods at higher probabilities of exceedance for all return periods. The results showed that an increase in the peak floods was to be expected, especially for small and middle floods. However, a distribution with the best goodness of fit could be used as a powerful tool for estimating and calculating the return period for the floods anywhere in the catchment, especially along rivers, dams and bridges to avert flood risks. The Gumbel and Log-Pearson Type III models predicted the highest floods which could be taken as the estimated limiting values for design purposes, especially for the 100 and 200 year return periods, whose values exceeded $1000 \mathrm{~mm}$ rainfall events.

\section{References}

[1] Dyson, L.L. \& van Heerden, J., Model for the identification of tropical weather systems over South Africa. Water SA, 28(3), pp. 249-258, 2002.

[2] Duaibe, K., Human activities and flood hazards and risks in the south west Pacific: a case study of the Navua catchment area, Fiji Islands. Published MSc thesis, University of Wellington, New Zealand, 2008, http://researcharchive.vuw.ac.nz/xmlui/bitstream/handle/10063/1004/thesi s.pdf? sequence $=2$

[3] Pegram, G. \& Parak, M., A review of the regional maximum flood and rational formula using geomorphological information and observed floods. Water SA, 30(3), pp. 377-384, 2004.

[4] Reason, C.J.C., Hachigonta, S. \& Phaladi, R.F., Interannual variability in rainy season characteristics over the Limpopo region of South Africa. International Journal of Climatology, 25(14): pp. 1835-1853, 2005.

[5] Drokin, A., MathWave Technologies, EasyFit Software v 5.5, USA, 2011.

[6] Gumbel, E.J., The return period of flood flows. Ann. Math. Statist, 12(2), pp. 163-190, 1941.

[7] Pearson, K., Contributions to the mathematical theory of evolution, II: Skew variation in homogeneous material. Philosophical Transactions of the Royal Society, 186, pp. 343-414, 1895.

[8] Sowetan, 10 dead, 4 missing after heavy rains. Published 22 January 2013, http://www.sowetanlive.co.za/news/2013/01/22/10-dead-4-missing-after$\underline{\text { heavy-rains }}$

[9] Mail \& Guardian, Limpopo region may be called disaster zone after 10 killed. Published 23 January 2013, http://mg.co.za/article/2013-01-23limpopo-region-may-be-called-disaster-zone-due-to-floods 
[10] SABC, Limpopo families left homeless after heavy rains. November 2015, http://www.sabc.co.za/news/a/7e46b2804ab044d08610bf17241b9ef9/Lim popo-families-left-homeless-after-heavy-rain--20151123

[11] Musyoki, A., Thifhulufhelwi, R. \& Murungweni, F.M., The impact of and responses to flooding in Thulamela Municipality, Limpopo Province, South Africa. Jàmbá: Journal of Disaster Risk Studies, 8(2), pp. 1-10, 2016. 